\title{
Guide of children's online activities by parents: A gateway to protecting and enhancing their appropriate development, secure their future and reduce burden on Public Health.
}

\author{
Ozurumba-Dwight LN $\mathbf{N}^{1 *}$, Gazama $\mathrm{UN}^{2}$ \\ ${ }^{1}$ Department of Public Health, Walden University, USA \\ ${ }^{2}$ Department of Biological Sciences, University of Maiduguri, Nigeria
}

\begin{abstract}
Children online activities are of various categories, some are beneficial and some harmful to their wellbeing and development. For instance, children make use of phones of various types to browse online, and utilize both personal and cybercafé computers (desktop and laptop systems) to browse.

Beneficial uses to which they engage online activities include search for information to- solve assignments they are given in school (Pre-college and college), play and download music (which relaxes the mind and body), download films for recreation (though some may teach them bad things and ideas), search for sports related information of their favorite sportsmen and teams, chat with friends for association and socials), and communicate with relations of distant geographical locations. Harmful effects includes- exposure to risk of being absorbed as members of terrorist groups under disguise, involvement in internet fraud and scams, download and watching of cartoon (fictional videos which may over glue them into an unreal world of excessive fantasies they could wrongly and fatally connect with as reality in life). It has been proven that overindulgence of children on virtual or fictional watching of films disconnects them from lessons, knowledge and real life cognitive experiences they are to learn from real life interactions with parents, guardians, good friends and good relations. These sort of lessons cannot be learnt by being over-glued on phone and computer screens watching fictional cartoon and playing games.

As such, this piece of review is significant and of positive value in supporting the rightful development of our children, in order to help secure their future, through reduction in the number of those who could be at risk of being plagued by the negative effects of children's online activities.
\end{abstract}

Keywords: Children, Online, Development, Cognitive, Protection, Health.

Accepted on August 17, 2020

\section{Introduction}

Children are usually regarded as the leaders of tomorrow. In developed countries with far reduced internal political and social problems like Canada, Irish Republic, the Scandinavian countries and some other unnamed countries in the developed world, their various governments strive so hard to build good structures of stable economies (politically, socially and financially) with necessary distortion cushions to give their born and unborn children a hope and a future. According to the Oxford Dictionary, a child is defined as a young being below the age of puberty or an immature person $[1,2]$ while the MerriamWebster Dictionary defines a child as a young person especially between infancy and youth. Various synonyms have been used for the term "child" such as-chap, bud, chick, cub, kid and juvenile. In contemporary English, the word "kid" is neither a slang nor improper. It isn't proper for formal usage. As such, in formally professional settings, the word child is preferred. In medical parlance, a child is either an unborn, recently born or a young person between infancy and youth or a young person $[3,4]$.

The internet offers speed of communication, convenience and anonymity, which children and adults can exploit in various activities that can be good or bad. These activities include "cyber enabled crime" (easily entered into by children) and "advanced cybercrime" (difficult to indulge in by children because it entails attacking computer hardware and software). On the other hand, mobile phones though pocket sized, are mini computers for online activities. As such, children can use phones to engage in calls and to surf the internet. These phones come in form of iPads, iPhones, Androids and other related gadgets with large memory sizes and capabilities for augmented memory through memory cardsn [3]. Due to the economic crunch in most countries in the developed world, and to the poor exchange rate of the currency of most underdeveloped and developing countries, children from these countries are prone to being lured through money brandished before them by sex tourists, leading to abuse of their integrity, future, health and life.

Myles Munroe, an accomplished author of motivational and Christian value books in the area of living a purposeful life, stated thus: "your beliefs are a product of your thoughts, your thoughts create your beliefs, your beliefs create your convictions, your convictions create your attitude, your attitudes controls your perceptions and your perceptions dictates your behavior" [4]. One-on-one interactions by true parents with their children can 
Citation: Ozurumba Dwight LN, Gazama U. Guide of children's online activities by parents: A gateway to protecting and enhancing their appropriate development, secure their future and reduce burden on Public Health. J Public Health Policy Plann April 2020;4(4):58-61

help guide the development of appropriate attitudes in children rather than allow diverse unmonitored materials to fill their thoughts and shape their attitudes towards life. In this wise, the wrong attitudes that lure children into cybercrimes are pertinent to mention here. These wrong attitudes by such children are difficult to neither blot out nor get controlled by children. They don't lead to self discovery for these children but to wasted destinies and future because some of these unfortunate children will likely end up losing their lives untimely or prematurely, being imprisoned for long periods, in terminal illnesses or psychological traumas that require lots of efforts by clinicians and psychologists to get them back on proper track of a life of purpose. Many of such children can't control their decisions, emotions and circumstances. The great Ralph Waldo Emerson once wrote, "What lies behind us and what lies before us are tiny matters compared to what lies within us" [5]. As such, parents ought to watch, monitor and control the nature of materials that their children feed themselves with online and on phone, which goes on to form their thoughts. These wrong thoughts form their beliefs, which in turn mold their attitude into wrong vices and these negative indulgences online; making them vulnerable to being abuse.

According to the World Health Organization (WHO), mobile phones are low-powered radiofrequency transmitters operating at frequencies between 450 and 2700 Mega Hertz (MHz), and transmits them when turned on. This radiofrequency waves do not ionize to cause harm to human beings, unlike radioactive rays like X-rays and Gamma rays that do so [6]. Phones are the most reliable means of communication globally, with over half of the population of many countries engaging phones. This indicates the importance of phones to daily life globally. The International Agency for Research on Cancer (IARC) and the WHO have jointly reported that radiofrequencies from phones have increased risk of causing glioma or meningioma forms of cancer for people who reported the highest $10 \%$ of cumulative hours on cell phone use, but no consistent trend in increasing risk with greater duration of use [6]. As such, radio frequencies from phones have been classified as only possibly carcinogenic to humans, and researches are ongoing by both agencies and other bodies in this field of science. It is speculative and requires time to unfold the true effects, due to the course and duration that cancer takes before it manifests.

Therefore, it becomes obvious that the use of phones and internet, alongside the diverse forms of activities carried out by these children on these devices, have their positive attributes and qualities. However, overindulgence on these devices ushers in negative effects on such children. Medical experts have proven that the brain of children normally develops rapidly during the child's first years and psychologists have followed this up by discovering that young children learn best by interacting with people and not with screens [7]. Children learn fast during early age; especially language, mathematics and communication skills. As such, the time they have to acquire these skills and related aptitudes should be adequate to enhance their development along the right path, alongside what they would be molded into; bearing in mind that negative activities on phone and online activities that they indulge in. This can take away their time for useful activities that will ultimately affect their cognition, social life, education, skills and aptitudes in positive ways.

\section{Significance}

Though the internet's social impact may involve building new relationships to strengthen existing ones, but only matured minds can sail through without being affected by the rays of the negative aspects as earlier highlighted. As such, these children need guidance and good information recourses from parents and guardians to be able to balance their time on it and avoid entering sites that are inimical to their development and future.

As far back as the year 2007, Kunkel, reported that the side effects of constant media exposure in children continues to be a growing Public Health concern. The relationship between online activities of children and social effects are intricately woven [8]. This indicates that studies are required to unravel areas of the good and bad sides of it, in order to make its usage more fruitful and of far reduced harm to children who are naïve about concepts of their activities that could affect their mental and physical development, as well as their future.

Over-indulgence and sedentary lifestyle can be a risk factor for obesity and may result in feeling of loneliness and depression [9].

\section{This systemic review has its objectives as}

$>$ Present relevant related data from previous literature on this subject.

$>$ Make inferences and harmoniously discuss this public health challenge based on the various retrieved support data.

$>$ Provide recommendations to Public health practitioners and policy formulators to help protect these naïve children.

\section{Relevant support data from past literature}

According to Jackson et al, in a study by this team, they reported that $16 \%$ of children were using email, $25 \%$ were instant messaging and $16 \%$ were participating in chat activities, from a pool of children they sampled. It is on record that more than two-thirds of 8-year old children in the developed world go online each day [10]. As such, they need parental guidance.

Children now watch these same violence driven films which they earlier started watching on the television in the past decades, now on the internet. Kunkel used a 40years period for a typical study and reported that exposure to violent portrayals poses a risk of harmful effects on children, with the harmful effects being grouped into three as follows: children's learning of aggressive attitudes and behaviors; increased callousness towards victims of violence; and increased fear of being victimized by violence [8]. The issue may not be just watching these violent films, but being chronically addicted to them that causes the psychological aftermaths of horror and various other havocs on fellow human beings and the society.

Many of the suicide bombings by Boko Haram terrorist group in Nigeria have been done by children recruits (used as child soldiers and many as suicide bombers, including females below 15 years who have been recruited through various sources in acts of child abuse). The terrorist group named Boko Haram recruited 2,000 children in 2016 and used them as child soldiers, says the United Nation Children's Fund (UNICEF) Executive named 
Mr. Anthony Lake, who disclosed this in Paris at a gathering of global leaders convened to discuss commitments by world leaders to end use of children in conflicts). While in 2013, an estimated 17,000 children were recruited in South Sudan and approximately 10,000 in Central African Republic. In the past 10years alone, more than 65,000 children have been released from aggrieved armed forces and groups, with tens of thousands of the boys and girls being of age 18 [11].

Recently, the Costa Rican government's interagency antitrafficking body called the National Coalition against Migrant Smuggling and Trafficking in Persons (CONNATT), reported identification of 23 victims of sex trafficking and forced labor in 2014 alone. These victims were from various countries of South America, some parts of North America and The Caribbean Islands. Unfortunately, authorities in this same country have identified adults using children to transport or sell drugs, adding that some of these children are trafficking victims [12].

\section{Discussion}

The beneficial activities on phone include- standard phone calls to communicate with relations and friends and learn the involved art, consciously or unconsciously development of skills and flair for technology, search to get information not found in their textbooks in order to solve problems or answer puzzles given them by their teachers, and development of personal aptitude for research. On the other hand, beneficial online internet activities of children include- development of aptitude for technology, to unwind and relax which refreshes the mind and thoughts, communicate with relations and good friends, develop good friendship and friends through online internet platforms which support their development and widening of knowledge base.

The apparently harmful "activities of children on phone" include communication with criminal groups that engage in financial crimes, money laundry, email and bank account hacking, high level sex tourism, terrorist groups with whom they establish contacts online, and examination malpractices, among others. Overindulgence or addiction to phone usage by these children has negative health and developmental effects on children [13].

Harmful "online internet activities" of children is mainly cybercrimes and includes connecting with criminal gangs and formally joining them (which initiates them into bank account hacking with these fraudulent swindlers of individuals and companies), prostitution through being recruited by high level sex tourists, being trafficked for work abroad with lots of hazards like enslavement and torture, supplying information to internet criminal gangs, and faking documents and certificates [14], for various fraudulent activities. According to the University of California Los Angeles UCLA Digital Media Centre and cited by Raise Smart Kid, overindulgence in use of internet by children makes them miss out of developing adequate skills for cognitive development and needed to understudy emotions [7]. Kids enlisted in terrorist groups are used for suicide bombing acts, as child soldiers and human shields during confrontation between government military forces and terrorist groups (for instance, as seen in Afghanistan, Pakistan and Nigeria where terrorist groups like ISIS in the Middle East and Boko Haram in West Africa, have wrecked physical, social and economic havoc, accompanied by tolls of lost lives).
Children obviously need help and protection against these tempting social evils and menace, noting that contacts and connections through the phone and internet interfaces are one of the avenues for their recruitment. From another angle in the area of crimes and involvement of use of phones and internet, in August 2016, the ring leader of a global crime network (simply named as Mr. Mike) who has been behind thousands of online scams was arrested in Rivers State, Nigeria, by Interpol and Nigeria's Economic and Financial Crimes Commission (EFCC) [13], a commendable feat. If children are not monitored with regards to their online and phone activities, to enhance their being protected from this type of criminal groups, they can fall victim of being used for their criminal activities or enlisting as full members. Due to the concerns on internet related crimes, it's a fact that Interpol is now working in partnership with COSPOL Internet Related Child Abuse Material Project (CIRCAMP) and Virtual Global Taskforce [14], to check this silent but lethal menace of internet related crimes.

During a child's early years after birth, when the brain develops rapidly, it is best for them to interact with people than with screens. Being head-down with phone screens and on internet interfaces, with vastly reduced eye contact with people have harmful effects on their brain development. According to the Psychologist Catherine Steiner-Adar, children need time-off their phones and online internet activities to cultivate skills to handle real life anxieties, create ideas that they process into insightful thoughts and share them with their parents for guidance that will help them direct their dreams [7]. They need vital interactions with parents, siblings and other kids who could be good kids. American Academy of Pediatrics AAP in its policy statement states that "kids as young as 15 months can learn from media when a caregiver is present and involved". This new guideline has shifted from the previous focus on "WHAT is on screen" to "WHO else is in the room" [15]. Apparently, this has been done to protect and promote adequate and appropriate positive development of children while endeavoring to vitally safeguard the future of learning from media on screens (involving phones or computers). Solo viewing by "kids" less than two years has been linked with deficient language skills and delays in language. For instance, for children between two and five years, the app for the screen program "Sesame Workshop" has been described as one of few high standard learning apps in the iPad store. As such, AAP recommends no more than one hour a day of screen use for this age group and that care givers take part in the screen time [15,16-20]. This corroborates the earlier stated facts in this systemic review and harmonized analysis.

If good guidance is given to our children, it would reduce burden on Public Health (arising from children who fall victim of the harmful effects-such as child abuse and its psychological damages, fractured family structures, children and teen-age drop out from schools [21], acute and chronic nutritional anomalies arising from ugly sides of child abuse and indulgence in terrorism among others) and burden on biomedical care (requiring clinical and laboratory investigations on affected children with repetitive motion injuries like carpal tunnel and eye strain, to help with appropriate diagnosis and therapy). 
Citation: Ozurumba Dwight LN, Gazama U. Guide of children's online activities by parents: A gateway to protecting and enhancing their appropriate development, secure their future and reduce burden on Public Health. J Public Health Policy Plann April 2020;4(4):58-61

\section{Conclusion}

In line with the foregoing, parents ought to monitor their children's phones and online activities. This can be done through parental measures that includes: making the in-built parental control device on their computers and smart phones functional, engaging in real life one-on-one study or reading out to their kids rather than just engaging them on eBooks on screen, installing more apps on educational games and interactive apps rather than non-educational games and visual apps to enhance their cognitive development, monitor the quality of material played with or watched and investing time to interact with their kids which is more important than the time their kids spend on the phone, and of course-reduction of their kid's time on phone and on online activities to a reasonable level. The educationist Kamenetz rightly summed up one of her write-ups on this subject by stating thus: "co-view with your children, help children understand what they are seeing, and help them apply what they learn to the world around them". This implies that the good things that children watch and see on screen becomes what they learn and forms their attitude towards life.

\section{References}

1. www.momjunction.com/articles/harmful-effects-of-mobilephones-on-kids.

2. Munroe M. The Spirit of Leadership: Cultivating the Attitudes That Influence Human Action. Whitaker House, PA: New Kensington, 2005; pp.300.

3. World Health Organization (WHO). Electromagnetic fields and public health: mobile phones. WHO 2017, Fact sheet No. 193.

4. www.raisesmatkids.com/all-ages/1-articles/smartphoneand-tablet-screen-time-good-or-bad-for-kids.

5. Kunkel D. The effects of Television violence on children. Hearing before the US Senate committee on commerce, Science and Transportation. 2007.

6. Psychological Association APA, Advocacy and Public Interest Government Relations. 2020.

7. Tokunaga RS, Rains SA. An evaluation of two characteristics of the internet use, time spent using the internet and psychosocial problems. Human Comm Res. 2010;36(4):512-45.

8. Jackson LA, Vo-Eye A, Biocca FA, et al. Children and internet use; Social, psychological and academic consequences for low-income children. Psychological Sc agenda 2003;12:1-4.
9. United State Department. Diplomacy in action: Trafficking in Persons 2016 Report. Office of monitor and combat trafficking in persons, Office of website management, Bureau of Public Affairs, The U.S. State Department. 2016.

10. American Academy of Pediatrics AAP. AAP Policy and Topic collections: Media use by children. Paediatrics.2020; 21:e625.

11. Interpol. Financial crimes. Interpol Digital Crime Centre. Cyber Defense Inst. 2017.

12. www.interpol.int/crime-areas/crime-against-children

13. Kamenetz A. America Academy of Pediatrics lifts "No screens under 2" Rule. NPR Ed. 2016;2:16.

14. United Nations Children Fund (UNICEF). Children at increased risk $\mathrm{f}$ harm online during global COVID-19 pandemic. Ind Edu Diary.2020;1.

15. World Health Organization (WHO). Adolescents: health risks and solutions. Released $13^{\text {th }}$ December 2018.

16. McDooL E, Powel P, Roberts J, et al. The internet and children psychological wellbeing. J Health Eco. 2020;69:102274.

17. Wang G, Zhao J, Zhang J, et al. Mitigate effect of home confinement on children during the COVID-19 outbreak. Lancet. 2020;395:945-947.

18. Livingstone $\mathrm{S}$. Rethinking the rights $\mathrm{f}$ children for the internet age. Children and the Media. London School Economics LSE Media Policy Project. 2019.

19. Festl R. Social media literacy and adolescent scial online behaviour in Germany. J Child Media. 2020;2:1-22.

20. Jimenez AG, Vozmediano MM. Subject matter f videos for teens on YouTube. Int J Adolesce Youths. 2019;25(1):6378.

21. Cortes-Paschal A, Cano-Escorianza J, Elbj-saso C, et al. Positive relationships for the prevention of bullying and cyberbullying: A study in Aragon (Spain). Int J Adolesce Youths. 2019;25(1):182-99.

\section{*Correspondence to:}

Ozurumba-Dwight

Department of Public Health

Walden University

USA

E-Mail: leon_ozurumba@yahoo.com 